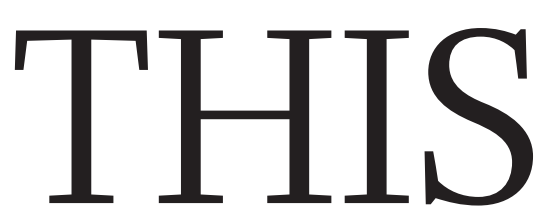

EDITORIALS
DEFAMATION Reforms to libel law unveiled in UK Parliament p.280
WORLD VIEW Evolution scientists

can do more to counter

creationists p.281
ASTEROID SCIENCE Giant space rock Vesta is more like a planet than an asteroid $\mathbf{p . 2 8 2}$

\title{
Misplaced childhood
}

\author{
The US National Institutes of Health should rethink plans to limit a nationwide study of children. \\ It must not miss a rare opportunity to probe the causes of childhood diseases.
}

$\mathrm{T}$ The US National Children's Study is at a crucial turning point. Established by Congress in 2000, the project is a highly ambitious, prospective study of biological and environmental influences on the health of 100,000 US children from before birth to age 21 . Twelve years on, the National Institutes of Health (NIH) in Bethesda, Maryland, has spent almost US $\$ 1$ billion to recruit roughly 4,000 participants (see page 287). Contrast that with the Norwegian Mother and Child Cohort Study, which recruited some 109,000 children - plus 163,000 of their parents - over a decade from 1999 at a cost of about $\$ 60$ million.

The NIH, rightly, decided that something must change. To continue on this trajectory would be ruinous - both for the agency's finances and for the scientific goals of the project. In response, it proposed dramatic changes earlier this year. These include a plan to recruit children through prenatal care providers, rather than by calling house to house. The NIH also wants to abandon the use of a sample of children designed by statisticians to represent all regions and population subgroups of the country, which would produce findings on both exposures and disease that could be applied to all US children. Instead, it has proposed to draw the bulk of subjects from health-maintenance organizations and large health-care providers.

The first move, away from door-to-door recruitment, makes perfect sense. In a sampling statistician's ideal world, that strategy would be the gold standard. But, as data from the pilot phase of the study show and most of those involved agree, it is simply too expensive. And it is slow. At current rates, it would take so long to recruit children that, given the rapidly changing nature of environmental exposures, it would undermine the scientific value of the study.

The second move, to dispense with a true national probability sample, is more troubling - and much more controversial. The US Institute of Medicine described the sampling method as one of the study's key strengths. The many critics of dropping it now include Edward Sondik, director of the National Center for Health Statistics at the Centers for Disease Control and Prevention (CDC) in Atlanta, Georgia.

It was CDC statisticians who developed the original list of 105 farflung study locations that the NIH now proposes abandoning. The range of places is important because it avoids selection biases that could lead to invalid inferences, and it represents the broad range of exposures and outcomes in a vast and demographically diverse nation.

The NIH should strengthen its commitment to gathering recruits from these diverse locations. Focusing on health-maintenance organizations, which tend to correspond to large population centres, will introduce inevitable sampling errors. It will also miss a rare opportunity to gather universally useful data on the incidence and prevalence of a plethora of childhood ailments and exposures.

Data on the true burden of many childhood illnesses is inadequate or absent. Yet this information forms the necessary basis to generate hypotheses about environmental exposures. And, as Congress intended, it is needed to discover the factors that contribute to rare and common conditions. By contrast, a skewed sample from large health-care providers, although undoubtedly more convenient and less costly, could produce estimates of disease risk that would not represent the face of the United States. For example, Kaiser Permanente - a large health-maintenance organization based in Oakland, California - might provide ready access to tens of thousands of potential recruits, but none of them lives in South Dakota or Minnesota.

The current NIH managers of the study say that they are closing in on a final sampling strategy for the main
"The NIH is damaging the public goodwill that is essential to the study's success."

\section{by appearing to jettison their commitment to run the study in the} by appearing to jettison their commitment to run the study in the 105 locations they announced with much fanfare several years ago, they are damaging the public goodwill that is essential to the study's long-term success.

The NIH should state unequivocally - and soon - whether it intends the full survey to be based on the national probability sample. If it concludes that doing so is financially untenable, then Congress should question whether the project will deliver what it asked for, and whether the tens of millions of dollars that flow annually to the study would be better spent on investigator-initiated grants that, however unpredictably, will move health and medicine forward for the coming generations.

\section{Needless conflict}

\section{Independent experts should be kept from undue suspicion as well as undue influence.}

W e are what we eat. So it should come as no surprise that foodrelated issues such as bovine spongiform encephalopathy (BSE), bisphenol A contamination, foot-and-mouth disease, Escherichia coli outbreaks and genetic modification resonate with the public. It is unfortunate, then, that discussion of them is often clouded by controversies over the impartiality of scientific advice and whether government regulations are truly unaffected by industry interests.

Questions of food safety, nutrition and agriculture elicit more emotion and public mistrust than almost any other science-based issue. The firestorm over obesity, for example, ignited once again in the United States last week, when the Institute of Medicine issued a 